International Review of Research in Open and Distributed Learning

Volume 21, Number 4

November - 2020

\title{
Editorial - Volume 21, Issue 4
}

Rory McGreal

Editor-in-Chief, Athabasca University

Welcome to the last IRRODL issue of 2020. I hope that all our readers are staying safe amid the spread of the worldwide COVID-19 pandemic. In this issue submissions from Malaysia, Iran, Turkey, Indonesia, Israel, France, Portugal, and the United States shed light on implementations of open and online learning in a wide variety of international contexts. This issue leads off with four articles investigating the student and teacher experiences in open, online learning followed by two articles relating features of the online learning environment in Iran. Then three articles on mobile learning, and lastly two submissions on MOOCs.

The first article, Identifying Student Perceptions of Different Instantiations of Open Pedagogy by Hilton, Hilton, Ikahihifo, Chaffee, Darrow, Guilmett, and Wiley describes instructional practices in open pedagogy and the perceptions of students who are charged with creating a syllabus. They conclude that there are a wide variety of approaches to open pedagogy and that more research is needed to examine its efficacy.

Teoh and Tan use online questionnaires and the technology acceptance model (TAM) in their study Predicting Behavioural Intention of Manufacturing Engineers in Malaysia to Use E-Learning in the Workplace. Their results conform the mediating role of perceived ease of use and usefulness, providing insights to guide organizations in designing online learning in the workplace.

Both students and faculty in a statewide community college system in the United States were surveyed in Gaddis' study, Faculty and Student Technology Use to Enhance Student Learning. Although the study provides no information on actual learning achievement, students report that the use of technology enhanced their learning and their preference for technology suggested that they were actively engaged, affecting positively their multimodal learning. This research could be used to inform strategic planning processes and institutional learning outcome development.

In Michaeli, Kroparo, and Hershkovitz's article, Teachers' Use of Education Dashboards and Professional Growth, dashboards were used as visual aids for reflection among Israeli elementary teachers. Using a framework roadmap for empowering learners' framework, they surveyed teachers finding that the use of dashboards was associated with professional growth. An additional qualitative study demonstrated which teachers benefited most from their dashboard use.

Samuel's contribution, Zones of Agency: Understanding Online Faculty Experiences of Presence introduces the Zones of Agency for Online Instructors model, which reveals five determinants of presence for online instructors: content, format, strategies, technology, and students. The crucial factor in 
determining instructors' experience of presence was the degree of agency the instructor had over these determinants.

E-learning in Iran is described in the next two articles. The first, E-Learning Challenges in Iran: A Research Synthesis by Kasani, Mourkani, Seraji, Rezaeizadeh, and Abedi analyses Iranian elearning studies and determined that the system faces problems in eight dimensions: legal, human, educational, technological, sociocultural, support, economic, and managerial-organizational. They suggest that their results could serve as a model for other countries with similar technology infrastructure and cultural features. Dashtestani focused on the perspectives of Iranian higher education stakeholders on the online teaching English as a Foreign Language (TEFL). Participants in this study showed significant improvement in their achievement in their online course; however, the survey identified several challenges in online learning: including lack of rigour', lack of credibility of certificates, lack of technological infrastructure, technical problems, lack of practical content, lack of human interaction, students' low knowledge of the content, and employers' lack of interest in employing graduates of online courses.

The following three articles investigate mobile learning, looking at teachers' beliefs and acceptance of mobile technologies, and mobile personal learning environments. The first of which takes us to Indonesia, where Saiful's mixed method study looks at Mobile Teacher Professional Development (MTPD): Delving into English Teachers' Beliefs in Indonesia. His qualitative and quantitative analyses showed favourable results in the majority of teachers' perception of the use of mobile devices.

In their study, Mobile Technology Acceptance Scale for Learning Mathematics: Development, Validity, and Reliability Studies, Açıkgül and Şad measured Turkish highs school students' level of acceptance of mobile technologies developing and implementing a Mobile Technology Acceptance Scale for Learning Mathematics (m-TASLM). Results were favourable in terms of validity and reliability.

Bidarra and Sousa examined two Portuguese distance learning courses to test the impact of mobile devices on personal learning environments (PLE) in their paper, Implementing Mobile Learning Within Personal Learning Environments: A Study of Two Online Courses. Their findings suggest that all students' have adapted well to mobile learning and that the learning resources available were more critical than either gender or age on the makeup of an individual's PLE.

The final two papers in this edition focus on MOOCs. Chaker and Bachelet's paper, Internationalizing Professional Development: Using Educational Data Mining to Analyze Learners' Performance and Dropouts in a French $M O O C$, employs data mining to study francophone learners' performance in different countries. Their investigation revealed disparities between students in partner institutions versus self-enrolled learners, in European learners versus learners in developing countries, and active versus inactive learners.

The last research paper in this issue, Heterogeneity of Learners' Behavioral Patterns of Watching Videos and Completing Assessments in Massive Open Online Courses (MOOCs): A Latent Class Analysis by Gu Kang makes use of latent class analysis to determine learner sub-groups: completing, disengaging, auditing, sampling, and enrolling. They suggest tailored instructional strategies to address the concerns 
of the at-risk sub-groups.

In the Notes From the Field section, Kotera, Green, Rhodes, Williams, Chircop, Spink, Rawson, and Okere at the University of Derby in the UK, expound on the benefits of morning virtual gettogethers, described as "huddles," for teachers newly-exposed to online learning due to the COVID-19 pandemic. In the next note, Finlayson describes the writing process and platform options in the creation of an OER course on World Geography.

In the Literature Review section, MOOCs are the subject of the following papers, the first is a systematic literature survey of MOOCs by Khalid, Lundqvist, and Yates and the second is a an extensive bibliometric analysis of growth and collaboration in MOOCs by Wahid, Ahmi, and Alam.

The Editors of IRRODL wish all our readers and their families in more than 80 countries all the best in the coming holiday season. Please stay safe and be careful during this pandemic.

\section{Athabasca}

University

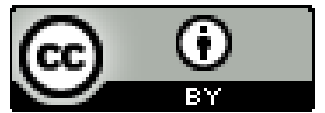

